\title{
Changes in Net Portal Nutrient Flux in Response to Weaning Transition and Ionophore Supplementation in Dairy Calves
}

\author{
J. L. Klotz ${ }^{1}$ and R. N. Heitmann ${ }^{2}$ \\ Department of Animal Science, The University of Tennessee, Knoxville 37996
}

\begin{abstract}
Dairy calf weaning is associated with ketone concentrations that exceed the levels occurring in adults, and weaning represents a potential energy loss that may be mitigated by ionophore supplementation. To assess the effects of weaning and ionophore supplementation on net nutrient flux across portal-drained viscera (PDV) tissues in dairy calves, concentrations of glucose, acetoacetate (ACAC), $\beta$-hydroxybutyrate (BHBA), nonesterified fatty acids, volatile fatty acids, lactate, pyruvate, insulin, and glucagon and PDV flux rates were determined in Jersey bull calves $(\mathrm{n}=19)$ at $35,56,84$, and $112 \mathrm{~d}$ of age. Calves were randomly assigned at birth to either a commercial pelleted starter without (CON) or with lasalocid (TRT; $83 \mathrm{mg} / \mathrm{kg}$ of dry matter). Calves were fed only milk replacer from d 3 to 34 (d 3 to $20=454 \mathrm{~g} / \mathrm{d} ; \mathrm{d} 21$ to $34=568 \mathrm{~g} / \mathrm{d}$ ). After blood sampling on d 35, calves received replacer (d 35 to $41=$ $454 \mathrm{~g} / \mathrm{d}$; d 42 to $48=227 \mathrm{~g} / \mathrm{d}$ ) and had free access to the CON or TRT starter, and from d 49 to 112 they received CON or TRT ad libitum. Catheters were implanted in the portal vein and in the mesenteric vein and artery between d 21 and 28. Blood flow was measured by continuous infusion of $p$-aminohippurate into the mesenteric vein. Six serial samples were taken at 30 -min intervals from the arterial and portal vein catheters simultaneously. Portal blood flow increased with age but did not differ between CON and TRT calves. Glucose was released preweaning and was extracted postweaning by PDV, but was not affected by ionophore. The portal flux of nonesterified fatty acids was not different from zero during any of the 4 sample ages. Fluxes of ACAC and BHBA in CON and TRT calves went from no measurable flux preweaning to a postweaning PDV release that peaked at $d 84$, but the $d-84$ release of ACAC and BHBA was lower in TRT calves. The portal flux of volatile fatty acids increased with age, and PDV release of both butyrate and propionate was lower at
\end{abstract}

\footnotetext{
Received June 16, 2006.

Accepted November 1, 2006.

${ }^{1}$ Present address: Forage-Animal Production Research Unit, USDA-ARS, Lexington, KY 40546

${ }^{2}$ Corresponding author: rheitman@utk.edu
}

d 84 in TRT than in CON calves. However, TRT calves had a greater PDV release of lactate on d 84, partially compensating for the lower release of propionate. Glucagon was greater in CON than in TRT calves at $d 84$ and could be a response to the elevated ketogenesis observed in $\mathrm{CON}$ calves during this period. Changes in the metabolic profile and nutrient flux of transition calves were demonstrated in response to weaning and ionophore supplementation. Inclusion of an ionophore appeared to moderate alimentary output at a postweaning period ( $\mathrm{d}$ 84) at which ketone concentrations have the potential to exceed the whole animal capacity for utilization.

Key words: nutrient flux, dairy calf, weaning, ionophore

\section{INTRODUCTION}

A defining characteristic of adult rumen epithelial tissue is the production of ketones, and in the fed animal, the rumen epithelium is the primary ketogenic tissue (Heitmann et al., 1987). However, the ketogenic capacity of the rumen epithelium is minimal from birth until periweaning (Giesecke et al., 1979; Baldwin and Jesse, 1992), and the liver is the primary source of ketone production during this period. The onset of ketogenic capacity in the rumen epithelium was previously thought to be the result of an age-independent relationship between DMI, subsequent VFA production, and onset of the ketogenic potential of the ruminal epithelium (Quigley et al., 1991a), but more recent reports have implicated an age-dependent ontological event (Lane et al., 2000; Lane et al., 2002). Nonetheless, dietary changes associated with weaning cause the rumen to undergo profound physical, morphological, and metabolic transformations. Complete oxidation of butyrate to carbon dioxide or the metabolism to ketones by the rumen epithelium of adults is concentration dependent, but does appear to be saturable when very high concentrations are encountered in vitro (Baldwin and McLeod, 2000) and in vivo (Kristensen and Harmon, 2004). Adult peripheral tissue uptake and utilization of either acetoacetate (ACAC) or BHBA measured in vivo are concentration dependent until concentrations greater than $2.0 \mathrm{~m} M$ are reached (Leng, 1965; Berg- 
man, 1971). Quigley et al. (1991a) reported postweaning peripheral ketone concentrations that approximated, and in some cases exceeded, this concentration limit. Because homeorhesis at weaning is not well understood, the potential could exist for a metabolic lag caused by a sudden influx of ketones that exceeds the rates of peripheral utilization.

The portal vein drains the rumen, entire small intestine, spleen, pancreas, and mesenteric and omental fat. Concentrations of metabolites released by these tissues, either exogenously or endogenously produced nutrients, are further modified by hepatic metabolism prior to release into the hepatic vein for distribution to peripheral tissues. There is an absence of information regarding the interorgan metabolic dynamics of splanchnic tissues in calves in relation to foregut development, specifically, the cause of hyperketonemia during weaning. This has led to the hypothesis that a concomitant reduction in alimentary ketogenesis and circulating ketone concentrations would improve calf performance during the weaning transition. Lasalocid is an ionophore frequently supplemented as an anticoccidial in commercially available calf starters and has been shown to cause a shift in ruminal fermentation patterns through a reduction in gram-positive bacteria, which are typically associated with the production of ketogenic precursors (Nagaraja et al., 1987). If it is possible to manipulate the proportions of VFA produced in the rumen, it should be possible to manipulate the proportions of energy substrates released into portal blood from the rumen. Therefore, the objectives of this study were to determine the effects of 1 ) weaning and 2) postweaning lasalocid supplementation on the net portal-drained viscera (PDV) flux of nutrients, insulin, and glucagon.

\section{MATERIALS AND METHODS}

\section{Animals and Management}

Calves and Housing. All procedures were conducted under protocols that were approved by the University of Tennessee Animal Care and Use Committee (protocol \#1004). Nineteen Jersey bull calves were obtained from the University of Tennessee Knoxville and Dairy Experiment Stations (Lewisburg, TN). Calves were left on-site until $3 \mathrm{~d}$ postpartum for adequate intake of colostrum and castration, and were then transported to the research unit at the Knoxville Experiment Station. Calves were housed in individual pens on rubber mat flooring for the duration of the experiment. Room temperature was set at $21.0^{\circ} \mathrm{C}\left( \pm 3.0^{\circ} \mathrm{C}\right)$ and artificial lighting was provided from 0600 to $1800 \mathrm{~h}$.

Diets and Feeding. Calves had ad libitum access to fresh water and trace-mineralized salt (Champions
Choice; Cargill Inc., Minneapolis, MN) for the duration of the study. Starting at $3 \mathrm{~d}$ of age, all calves received $227 \mathrm{~g}$ of commercial milk replacer brought to an approximate volume of $1.9 \mathrm{~L}$ with $\mathrm{H}_{2} \mathrm{O}$ (12\% solids, wt/vol; Instant Nursing Formula NT Medicated; Land O'Lakes Animal Milk Products Co., Fort Dodge, IA) twice daily at 0800 and $1630 \mathrm{~h}$ from nipple bottles. At $21 \mathrm{~d}$ of age, the milk replacer ration was increased to $284 \mathrm{~g}$ per $1.9 \mathrm{~L}$ of $\mathrm{H}_{2} \mathrm{O}$ ( $15 \%$ solids, wt/vol). The first of 4 blood samplings was conducted at $35 \mathrm{~d}$ of age, and upon completion of sampling a commercially prepared high-fiber calf starter (CO-OP Calf Primer-I or Calf Primer-I-B; Tennessee Farmers Cooperative, Lavergne, TN) was offered for ad libitum consumption. From d 35 to 42 , calves were still receiving milk replacer twice daily, but the ration was reduced to $227 \mathrm{~g} / 1.9 \mathrm{~L}$. Starting at wk 6 (d 42), only the a.m. replacer ration was offered, and at wk 7 (d 49) calves were weaned. Calves with scours were treated with a commercial oral electrolyte solution (Revitilyte; Vets Plus, Inc., Knapp, WI) that was fed between the a.m. and p.m. milk replacer feedings (1200 h). No surgery or blood sampling was conducted on calves with scours.

Calf starter diets were commercially prepared and pelleted without (CON) or with lasalocid (TRT) supplement ( $83 \mathrm{mg} / \mathrm{kg}$ of DM). Calves were randomly assigned to either the CON $(n=12)$ or TRT $(n=7)$ starter at birth. Starter was fed in a single ration at $0800 \mathrm{~h}$ (initially $0.9 \mathrm{~kg}$ ). When a calf consumed an entire ration, the subsequent ration was increased by $105 \%$ of the previous day's consumption. Feed ration and refusal amounts were recorded daily.

\section{Surgery}

Preoperative Procedures and Anesthesia. A presurgical subcutaneous dose (44,000 U/kg of BW) of Penicillin Procaine-G (US Vet; Hanford Pharmaceuticals, Syracuse, NY) was administered before surgery. Because the calves were receiving only milk replacer at the time of the surgery, only the a.m. ration was withheld on the day of surgery. Water and trace-mineralized salt blocks were removed during this fasting period. Prior to surgery, calves were initially anesthetized with a halothane-oxygen mixture $(5 \%$ halothane at $2.0 \mathrm{~L} /$ min of $\mathrm{O}_{2}$ ) using a face mask. Immediately after the loss of mandible tension and swallowing reflex, calves were intubated with an endotracheal tube $(9.5 \mathrm{~mm}$ i.d.; Mallinckrodt Inc., St. Louis, MO) through which surgical anesthesia was introduced and maintained ( $2 \%$ halothane at $2.0 \mathrm{~L} / \mathrm{min}$ of $\mathrm{O}_{2}$ ).

Surgical Procedures. Between wk 3 and 4 postpartum, calves were surgically fitted with chronic, indwelling catheters (Tygon; Norton Performance Plas- 
tics, Akron, OH) equipped with Silastic (Helix Medical, Inc., Carpenteria, CA) cuffs in the mesenteric and hepatic portal veins and in the mesenteric artery using techniques first developed by Bergman (Katz and Bergman, 1969) and modified by Zanzalari et al. (1989). Catheters were exteriorized in the dorsolumbar region via a sterile skin needle and inserted into a denim pouch that was attached between the first and third lumbar vertebrae. Catheters were flushed and filled with sodium heparin (1,000 USP units/mL; Elkins-Sinn, Cherry Hill, NJ).

Postoperative Care. Following surgery, the calf was placed on its sternum in a padded recovery room and closely supervised until it was able to stand without assistance. The calf was offered a p.m. ration of milk replacer upon successful recovery. A second dose of penicillin was administered following surgery and at 12-h intervals for $4 \mathrm{~d}$ thereafter. Calves were also treated with flunixin meglumine (Banamine, $1.1 \mathrm{mg} / \mathrm{kg}$ of BW; Schering-Plough Animal Health Corp., Union, NJ) following surgery and the following day to minimize discomfort. All external suture lines were treated daily with a liberal application of an antimicrobial ointment (Nolvasan antiseptic ointment; Fort Dodge Animal Health, Fort Dodge, IA). Rectal temperature was recorded for all animals twice daily postsurgery for the remainder of the experiment.

\section{Measurements}

Blood Sampling. Net metabolite fluxes across the PDV tissue bed were quantified from blood samples taken at $35,56,84$, and $112 \mathrm{~d}$ postpartum ( 2 wk preweaning and 1, 5, and 9 wk postweaning). Sampling was conducted in the environment to which the animals were accustomed. During sampling, calves had normal access to feed and water as described above. Prior to sampling, a 23-mL pulse-dose of sterile $p$-aminohippurate (PAH) was infused into the mesenteric vein catheter (PAH was sterilized by vacuum filtration through a bottle-top filter with $0.22-\mu \mathrm{m}$ membrane porosity). Following the pulse-dose, sterile PAH was infused for $1 \mathrm{~h}(1.5 \%$, wt/vol, at $0.764 \mathrm{~mL} / \mathrm{min}$; model 200 ; $\mathrm{KD}$ Scientific, New Hope, PA) with a $50-\mathrm{mL}$ glass syringe (Becton Dickinson, Franklin Lakes, NJ). Following the 1-h equilibration period, 6 serial 15-mL blood samples were taken simultaneously from the mesenteric artery and portal vein at 30-min intervals. Infusion of PAH was continuous throughout the blood sampling period. Samples were collected in $20-\mathrm{mL}$ syringes that contained $400 \mu \mathrm{L}$ of $\mathrm{Na}_{2}$ EDTA (6\%, wt/vol). Because the heparin used to maintain catheter patency is known to activate lipoprotein lipase and generate inaccurate measures of NEFA, the catheter contents were replaced with only $0.9 \%$ physiological saline between samples. Whole blood samples were kept on ice until analyzed, and samples for ketones, lactate, pyruvate, glucose, and PAH were deproteinized prior to transport to the laboratory.

BW and Feed Samples. Prior to feeding, calves were weighed the same day each week for the entirety of the study. Body weight measures were also recorded at birth, weaning, and termination of the study, and on each blood sampling day. All diets in this study were commercially prepared and were obtained in a single shipment with the same lot number. Feeds (milk replacer and calf starters) were sampled monthly and composited for composition analysis.

\section{Chemical Analyses}

Blood Samples. Analysis for arterial packed-cell volume was done as samples were collected using a microhematocrit centrifuge and microcapillary reader (International Equipment Co., Needham Heights, MA). Whole blood samples were analyzed for concentrations of $\mathrm{PAH}$, glucose, L-(+)-lactate, pyruvate, ACAC, and BHBA. Spectrophotometric analyses for PAH, glucose, ACAC, and BHBA were performed the same day as sampling. Deproteinized lactate and pyruvate samples were centrifuged $\left(1,600 \times g\right.$ at $\left.4^{\circ} \mathrm{C}\right)$, and supernatants were collected and frozen $\left(-20^{\circ} \mathrm{C}\right)$ for analysis within 2 wk. Plasma was harvested from the remaining blood sample following centrifugation at $1,600 \times g$ at $4^{\circ} \mathrm{C}$ and stored at $-20^{\circ} \mathrm{C}$ for later analyses of NEFA, VFA, glucagon, and insulin.

p-Aminohippurate was measured as described in Kaufman and Bergman (1971). Analyses for BHBA and ACAC were done using the enzymatic assays of Williamson and Mellanby (1974) and Mellanby and Williamson (1974), respectively. L-(+)-Lactate and pyruvate were determined using the procedures from Sigma kits modified for use on a microtiter plate reader for lactate and pyruvate (\#726-UV and \#826-UV, respectively; Sigma Chemical Co., St. Louis, MO). Analysis of NEFA was done using the Wako NEFA-C kit (Wako Chemical USA, Dallas, TX). Blood glucose was determined using the Sigma glucose kit (\#510; Sigma Chemical Co.). Plasma glucagon and insulin were determined using the double-antibody RIA and the CoatA-Count insulin kits and protocols, respectively, from Diagnostics Products Corporation (Los Angeles, CA). For hormones and NEFA, intraassay errors greater than $10 \%$ were not accepted and samples were rerun. Plasma VFA analysis was done using the procedures described by Reynolds et al. (1986), with modifications by Quigley et al. (1991b) and Benson et al. (2002). Samples were analyzed with a Hewlett-Packard gas chro- 
Table 1. Chemical composition of feeds ${ }^{1}$

\begin{tabular}{lccc}
\hline & $\begin{array}{c}\text { Milk } \\
\text { Item }\end{array}$ & & \\
\hline $\mathrm{DM}, \%$ & 93.77 & 91.01 & 90.98 \\
$\mathrm{CP}, \%$ & 22.69 & 19.85 & 19.09 \\
Ether extract, \% & 19.55 & 2.87 & 2.89 \\
NDF, \% & 0.39 & 33.18 & 34.45 \\
$\mathrm{ADF}, \%$ & 0.14 & 17.71 & 18.67 \\
Ash, \% & 12.46 & 7.75 & 7.75 \\
Calcium, g/kg & 7.04 & 8.82 & 8.54 \\
Phosphorus, g/kg & 9.95 & 7.93 & 7.51 \\
Magnesium, g/kg & 1.62 & 3.66 & 3.64 \\
Potassium, g/kg & 28.21 & 12.89 & 12.80 \\
Gross energy, Mcal/kg & 4.96 & 4.34 & 4.33 \\
\hline
\end{tabular}

${ }^{1}$ Milk replacer was Instant Nursing Formula (Land O'Lakes, Fort Dodge, IA) and calf starters were Calf Primer-I (control) and Calf Primer-I-B (treatment; Tennessee Farmers Cooperative, Lavergne, TN).

${ }^{2}$ Composition on a DM basis.

${ }^{3}$ Treatment calf starter was formulated to contain the lasalocid supplement at $83 \mathrm{mg} / \mathrm{kg}$ of DM.

matograph (5890A), autosampler (7637A), integrator (3393A), and a J\&W Scientific 530- $\mu \mathrm{m}$ HP-FFAP capillary column $(10 \mathrm{~m} \times 0.53 \mathrm{~mm} \times 1 \mu \mathrm{m}$ i.d.; Agilent Technologies Inc., Palo Alto, CA) using He as the carrier gas at $100 \mathrm{~mL} / \mathrm{min}$. Volatile fatty acid concentrations were corrected for recovery of 2 -ethylbutyric acid, the internal standard.

Feed Samples. Composite dietary samples of the CON and TRT starters were ground through a 1-mm screen in a Wiley mill (Arthur H. Thomas Co., Philadelphia, PA) and analyzed with the composite milk replacer sample for DM, N (model FP-2000 nitrogen analyzer; Leco, St. Joseph, MI), gross energy (model 1241 adiabatic calorimeter; Parr Instruments, Moline, IL) ether extract (AOAC, 1999), NDF and ADF (Ankom Technology, 2003a,b; Ankom 200 series fiber analyzer, Ankom Technology Corp., Macedon, NY), and minerals (Unicam Solaar 969 atomic absorption spectrometer; Unicam, Cambridge, UK). Chemical compositions of the milk replacer and TRT and CON calf starters are shown in Table 1.

\section{Calculations}

The equations used to determine blood flow and net flux rates were published in full by Heitmann and Fernandez (1986). The values reported are net fluxes and represent a combination of metabolite uptake and release. These values are not unidirectional flux rates and cannot differentiate absorption, interconversion, and release of a metabolite from de novo production and release of a metabolite. A positive net flux indicates the net release or production of a metabolite, and a negative net flux indicates net uptake or tissue utiliza- tion of a metabolite by the specific tissue (Heitmann, 1989).

\section{Statistical Analyses}

This experiment was originally designed as a randomized complete block that blocked calves in groups of 2 by birth date and weight and incorporated age at sampling as a repeated measures treatment design. Difficulties associated with catheter patency limited the ability to obtain samples from both the arterial and portal catheters at each of the 4 sampling periods for both control and treatment calves within a block. This resulted in a considerable number of incomplete blocks or a variety of different combinations of catheters sampled between calves within a block. In addition, sparse data across the 4 sampling ages resulted in nonconvergence of the maximum likelihood solution for covariance parameter estimates when week was used as a repeated measure. Thus, block effect was dropped from the model and age at sampling (week) was used as a fixed factor instead of as a repeated measure.

All statistical analyses were conducted using mixedmodel procedures of SAS (version 8.2; SAS Inst., Inc., Cary, NC). Data for blood variables, net fluxes, and weekly BW were analyzed as a completely randomized design. Data obtained from each sampling site were analyzed separately. Analyses of variance for measured variables were performed with effects of diet (starter with or without lasalocid), age (week), and diet $\times$ age in the model. The statistical model used was

$$
\mathrm{Y}_{\mathrm{ijk}}=\mu+\mathrm{D}_{\mathrm{i}}+\mathrm{W}_{\mathrm{j}}+\mathrm{D} \times \mathrm{W}_{\mathrm{ij}}+\mathrm{R}(\mathrm{D} \times \mathrm{W})_{\mathrm{ijk}}
$$

where $Y_{i j k}$ is the dependent variable, $\mu$ is the overall mean, $D_{i}$ is the effect of diet $i, W_{j}$ is the effect of week $\mathrm{j}$ (age at sampling), $\mathrm{D} \times \mathrm{W}_{\mathrm{ij}}$ is the effect of the diet $\times$ week interaction, and $R(D \times W)_{i j k}$ is the effect of calf (replicate) $\mathrm{k}$ nested within the diet $\times$ week (residual error).

The individual means presented are averages of the 6 serial blood samples (one observation) taken and averaged across all replicates ( $\mathrm{n}=$ number of calves) for each metabolite for each week. Student's $t$-tests were also used to ascertain whether portal-arterial concentration differences differed from zero. Calf numbers vary among measured values because of problems with calf mortality and catheter patency. Because of the unbalanced number of observations, all data are presented as least squares means \pm SE. Significant treatment interactions were separated using the least significant difference features in SAS. Effects were considered significant at $P \leq 0.05$ and are discussed as having a tendency to be significant at $P \leq 0.10$. 


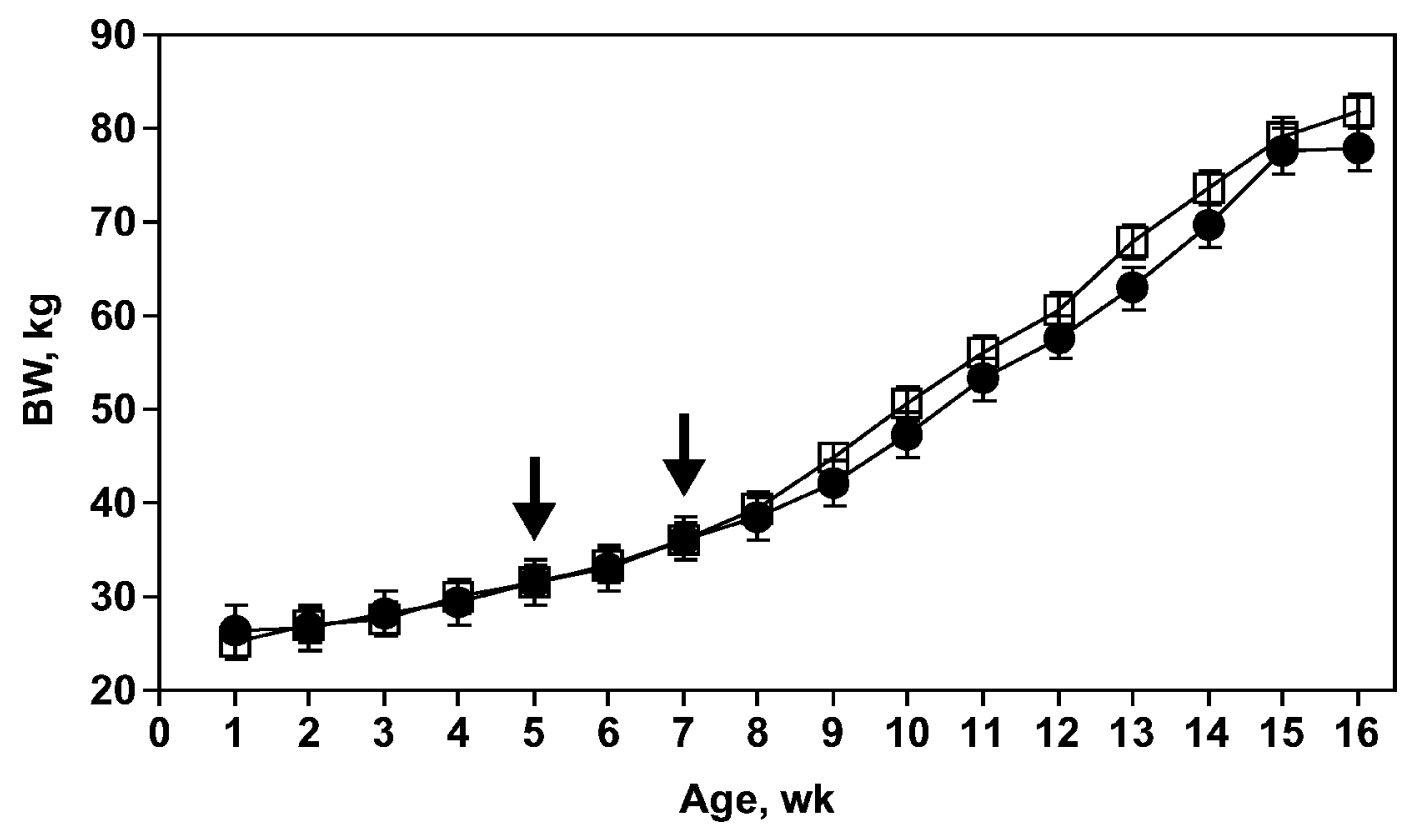

Figure 1. Effects of calf starter supplemented with $(\mathbf{0} ; n=7)$ or without lasalocid $(\square ; \mathrm{n}=12)$ on weekly BW. Arrows indicate initiation of the starter ration at wk 5 and cessation of the milk replacer ration at wk 7 . All values are means $\pm \mathrm{SE}$, and from wk 5 to 16 the effect of diet was significant $(P<0.05)$.

with the concentrations measured in CON calves being greater than those in TRT calves at d $56(P<0.05)$. However, by d 84 lactate concentrations were higher in TRT than in CON calves $(P<0.05)$. Pyruvate concentrations (Table 4) increased from d 35 to 56 in CON calves and then remained constant. However, pyruvate

Table 3. Blood flow in preweaning and postweaning dairy calves receiving calf starter with (treatment) or without (control) lasalocid

\begin{tabular}{|c|c|c|c|c|c|c|c|}
\hline \multirow{3}{*}{$\begin{array}{l}\text { Item and } \\
\text { dietary } \\
\text { assignment }^{1}\end{array}$} & \multirow{2}{*}{\multicolumn{4}{|c|}{ Day of age ${ }^{2}$}} & \multicolumn{3}{|c|}{ Effect $^{3}$} \\
\hline & & & & & \multirow{2}{*}{$\begin{array}{l}\text { Diet } \\
\text { (D) }\end{array}$} & \multirow{2}{*}{$\begin{array}{c}\text { Age } \\
(\mathrm{A})\end{array}$} & \multirow[b]{2}{*}{$\mathrm{D} \times \mathrm{A}$} \\
\hline & 35 & 56 & 84 & 112 & & & \\
\hline & \multirow{2}{*}{\multicolumn{4}{|c|}{ (Blood flow, $\mathrm{L} / \mathrm{h})$}} & \multirow{4}{*}{ NS } & \multirow{4}{*}{$<0.01$} & \multirow{4}{*}{ NS } \\
\hline \multirow{3}{*}{$\begin{array}{l}\text { Portal vein } \\
\text { Control } \\
\text { Treatment }\end{array}$} & & & & & & & \\
\hline & $145.5^{\mathrm{d}} \pm 19.9$ & $223.3^{\mathrm{c}} \pm 22.2$ & $377.4^{\mathrm{ab}} \pm 22.2$ & $416.8^{\mathrm{a}} \pm 25.7$ & & & \\
\hline & $117.3^{\mathrm{d}} \pm 22.2$ & $236.3^{\mathrm{c}} \pm 19.9$ & $342.6^{b} \pm 22.2$ & $422.9^{a} \pm 25.7$ & & & \\
\hline Portal vein & & & & & NS & $<0.01$ & NS \\
\hline Control & $4.3^{\mathrm{bc}} \pm 0.3$ & $5.2^{\mathrm{ab}} \pm 0.3$ & $5.8^{\mathrm{a}} \pm 0.4$ & $5.2^{\mathrm{ab}} \pm 0.4$ & & & \\
\hline Treatment & $3.7^{\mathrm{c}} \pm 0.3$ & $5.4^{\mathrm{a}} \pm 0.3$ & $5.5^{\mathrm{a}} \pm 0.3$ & $5.0^{\mathrm{ab}} \pm 0.4$ & & & \\
\hline Portal vein & & & & & NS & $<0.01$ & NS \\
\hline Control & $111.2^{\mathrm{d}} \pm 14.1$ & $166.8^{\mathrm{c}} \pm 15.7$ & $270.0^{\mathrm{ab}} \pm 15.7$ & $294.2^{\mathrm{a}} \pm 18.2$ & & & \\
\hline Treatment & $84.6^{\mathrm{d}} \pm 15.7$ & $166.7^{\mathrm{c}} \pm 14.1$ & $241.7^{b} \pm 15.7$ & $290.2^{\mathrm{a}} \pm 18.2$ & & & \\
\hline
\end{tabular}

${ }^{\mathrm{a}-\mathrm{e}}$ Means within a row and between dietary treatments not sharing like superscripts are different $(P<$ $0.05)$.

${ }^{1}$ Control starter: $d 35(n=5)$, d 56 and $84(n=4)$, and d $112(n=3)$. Treatment starter: Days 35 and d $84(\mathrm{n}=4)$, d $56(\mathrm{n}=5)$, and d $112(\mathrm{n}=3)$.

${ }^{2}$ Calves were weaned on d 49 , and prior to d 35 , no starter was offered to calves. Day 35 is preweaning; thus, samples were taken when calves were consuming only milk replacer and there was no dietary treatment. Calves are listed by their postweaning dietary assignment to demonstrate no preexisting differences prior to initiation of the dietary treatment and to permit comparison across all 4 sampling periods.

${ }^{3}$ Probability of a greater $F$ statistic; not significant (NS) at $P>0.10$. 
Table 4. Arterial concentrations of metabolites in preweaning and postweaning dairy calves receiving calf starter with (treatment) or without (control) lasalocid

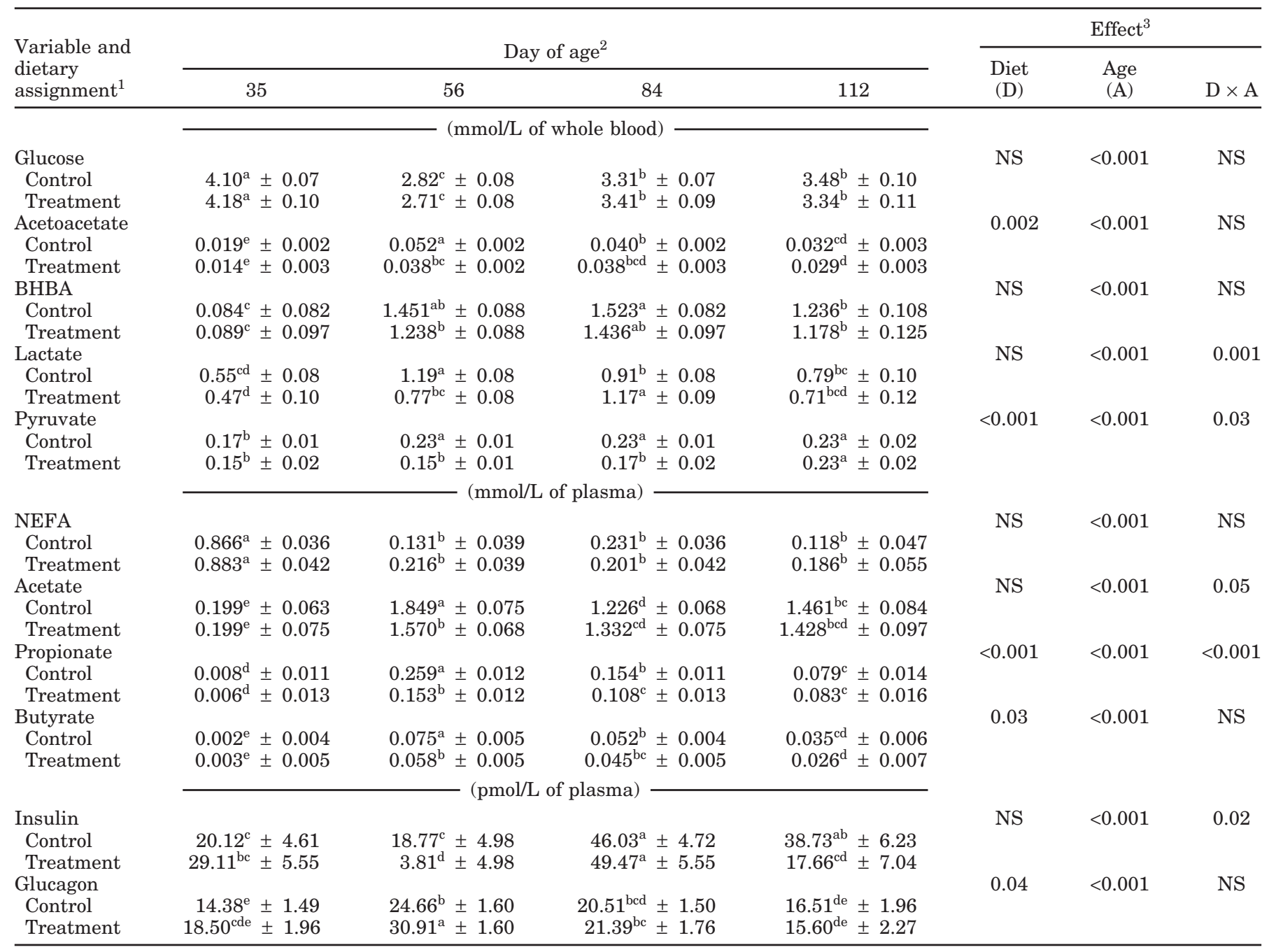

${ }^{\mathrm{a}-\mathrm{e}}$ Means within a row and between dietary treatments not sharing like superscripts are different $(P<0.05)$.

${ }^{1}$ Control starter: $d 35$ and $84(n=7)$, d $56(n=6)$ except for acetate $(n=5)$, and d $112(n=4)$. Treatment starter: Day 35 ( $\left.n=5\right)$ except for glucose, lactate, and glucagon $(\mathrm{n}=4)$; d $56(\mathrm{n}=6)$; d $84(\mathrm{n}=5)$; and d $112(\mathrm{n}=3)$.

${ }^{2}$ Calves were weaned on d 49, and prior to d 35, no starter was offered to calves. Day 35 is preweaning; thus, samples were taken when calves were consuming only milk replacer, and there was no dietary treatment. Calves are listed by their postweaning dietary assignment to demonstrate no preexisting differences prior to initiation of dietary treatment and to permit comparison across all 4 sampling periods.

${ }^{3}$ Probability of a greater $F$ statistic; not significant (NS) at $P>0.10$.

concentrations in TRT calves did not increase until d 112 and were lower than those in CON calves at $\mathrm{d} 56$ and $84(P<0.05)$.

There was a diet effect for ACAC $(P<0.05)$, but not one for BHBA $(P=0.19$; Table 4$)$. Substantial increases in concentrations of ACAC and BHBA in both CON and TRT calves were associated with weaning. Concentrations of ACAC (Table 4), but not BHBA, were affected by diet. Day-56 concentrations of ACAC were greater $(P<0.05)$ in CON than in TRT calves. In CON and TRT calves, ACAC and BHBA concentrations peaked on sampling d 56 and 84, respectively.
Acetate, propionate, and butyrate arterial concentrations (Table 4) were all greater in CON than in TRT calves $1 \mathrm{wk}$ postweaning on d $56(P<0.05)$. Concentrations of all VFA were greatest at d 56 for both CON and TRT calves. Unlike the acetate and butyrate concentrations, which did not differ between CON and TRT calves at d 84 and 112 , propionate concentrations were still greater in CON calves at d 84, but not at d 112 .

Insulin arterial concentrations (Table 4) were variable across the 4 sample days. In CON calves, insulin did not change until d 84, but in TRT calves insulin concentrations decreased and were lower than those in 
CON calves $(P<0.05)$ at d 56 and 112 . Conversely, glucagon concentrations on d 56 were significantly greater in TRT than in CON calves. There was a noticeable increase in glucagon concentrations between $\mathrm{d} 35$ and 56. Glucagon concentrations at d 84 and 112 were not different between diets, but glucagon concentrations in TRT calves decreased between d 84 and d 112 (Table 4).

\section{PDV Net Fluxes}

Portal-arterial concentration differences are presented in Table 5. Student's $t$-tests were used to determine whether the portal-arterial concentration differences differed from zero. A significant difference would reflect net flux. All references to Table 5 that follow were used to substantiate a significant net portal flux. Age affected all PDV fluxes of blood and plasma metabolites (Table 6). There was a net PDV release of glucose on d 35 only. There were no significant fluxes of glucose across PDV (Table 5) during subsequent postweaning measures and no effect of age or calf starter. Lactate and acetate also had a net PDV release at $d$ 35. Unlike glucose, however, the net portal releases of lactate and acetate remained significant (Table 5) and continued to increase across sampling periods. By d 84 (5 wk postweaning), calves receiving the lasalocid-supplemented starter had a higher net PDV release of lactate than did CON calves $(P<0.05)$. Conversely, the PDV release of propionate was lower in TRT calves at $\mathrm{d} 84$ than in CON calves $(P<0.05)$. On d 84 and 112 , TRT calves had a net PDV uptake of pyruvate (Table 6) that was almost $50 \%$ lower than that in CON calves $(P$ $<0.05$ ).

By d 56 (1 wk postweaning), both groups of calves had been receiving their respective starters for $3 \mathrm{wk}$. Cessation of the portal appearance of glucose coincided with the portal releases of ACAC and BHBA. There was an 11-fold increase in the PDV release of acetate from d 35 to 56 (Table 6), and the portal releases of propionate and butyrate became significant (Table 5). Interestingly, at d 56 the net portal release of propionate was numerically greater than that of acetate for both CON and TRT calves. There was a significant diet effect for acetate, butyrate, and BHBA, and there tended to be one for ACAC and propionate (Table 6). Net portal releases of ACAC and BHBA increased substantially postweaning and reached maximum releases by $d 84$. Net PDV fluxes of butyrate, ACAC, and BHBA at $\mathrm{d} 84$ were greater in CON than in TRT calves $(P<$ 0.05). By d 112, net portal releases of VFA and ketones no longer differed between diets or from the previous sampling day.
The net releases of insulin and glucagon (Table 6) did not differ between d 35 and 56 , but were greater on d 84 and 112 for both CON and TRT calves $(P<$ 0.05). For insulin flux, there was a significant age effect, but for glucagon, the effects of diet, age, and diet $\times$ age interaction were all significant. The net PDV release of glucagon was lower in TRT than in CON calves only on d $84(P<0.05)$.

\section{DISCUSSION}

\section{Effects of Surgery}

The results of lasalocid supplementation on BW and performance characteristics (Figure 1 and Table 2) did not demonstrate any differences, and the similarity between CON and TRT pretreatment comparisons indicated that no preexisting differences influenced the measurements taken after the dietary treatment was initiated. These findings agree with those observed in a companion experiment (Klotz and Heitmann, 2006). Although no statistical comparisons can be made between the 2 experiments, overall and preweaning ADG were numerically the same, but postweaning ADG appeared slightly lower in the current experiment. This may have been a consequence of calves in this experiment having undergone surgery. Also, calves in this experiment had numerically lower DMI and feed efficiency than those in the previous study (Klotz and Heitmann, 2006), which may have been a result of calves in the present experiment being housed in a controlled environment vs. calves in the previous experiment being housed outdoors during cool-season months. However, overall similarities in the findings between the 2 experiments suggest that the performance of calves in the current experiment was not affected by surgery to a degree that would confound the results reported and their interpretation.

\section{Blood Flow}

The lowest portal blood flow rates were observed at d 35 (preweaning) at 145.5 and $117.3 \mathrm{~L} / \mathrm{h}$ for CON and TRT when calves were receiving only milk replacer. These values are similar to the previously published preruminant portal blood flow rates of 159.8 (a calculated mean of 24 hourly measurements; Ortigues et al., 1995), 145.8 (Carr and Jacobson, 1968), and 141.2 L/h (Durand et al., 1988).

As calves increased in size, the portal blood flow increased significantly with each sampling day, resulting in a greater flow rate than the preceding measure (Table 3). When these data were corrected for BW (Table 3 ), only d 35 remained significantly different from the other sample periods. This is suggestive of an increase 
Table 5. Portal-arterial concentration differences of metabolites in preweaning and postweaning dairy calves receiving calf starter with (treatment) or without (control) lasalocid

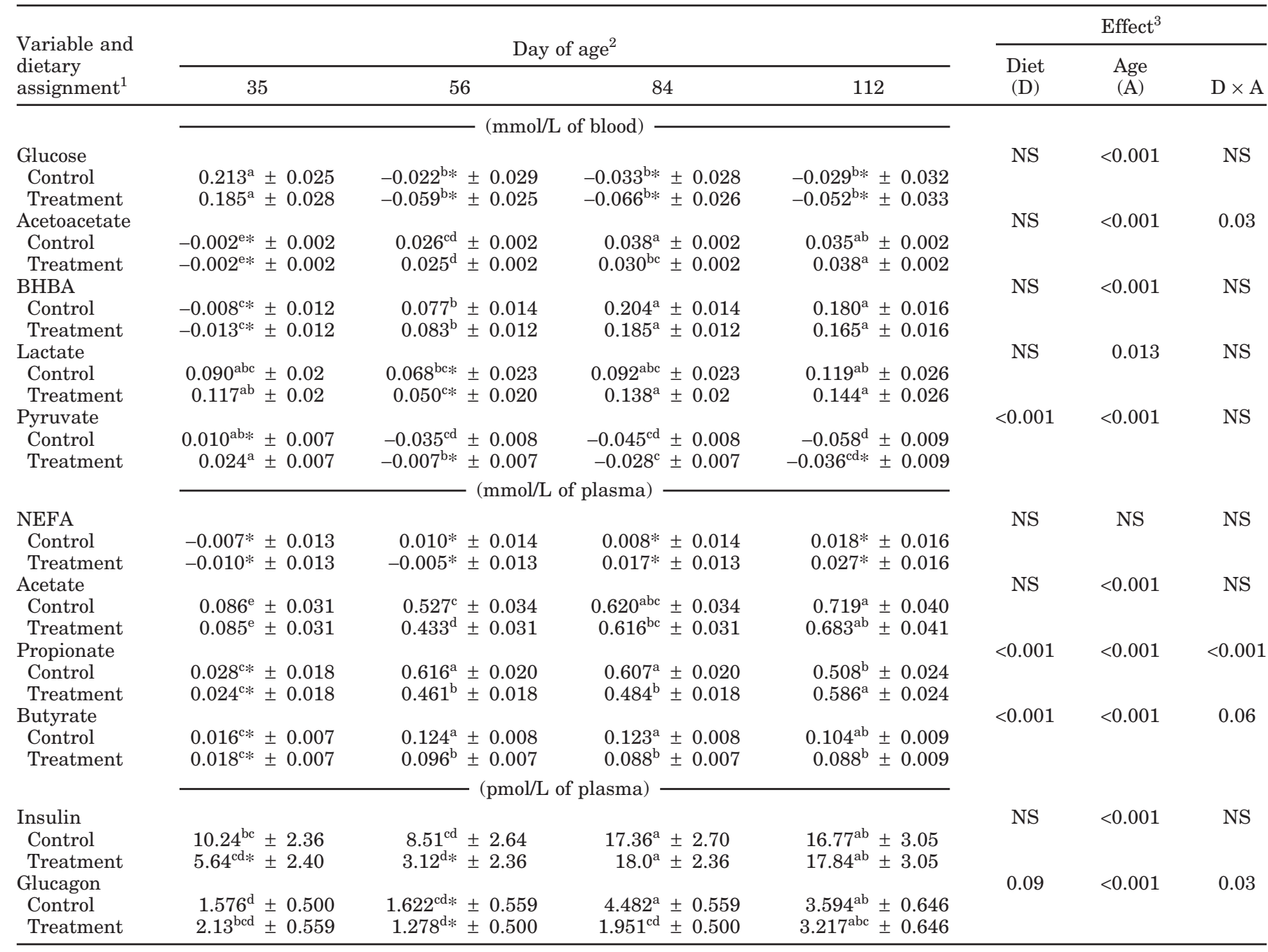

${ }^{\mathrm{a}-\mathrm{e}}$ Means within row and between dietary treatment not sharing like superscripts are different $(P<0.05)$.

${ }^{1}$ Control starter: d $35(\mathrm{n}=5)$, d 56 and $84(\mathrm{n}=4)$, and d $112(\mathrm{n}=3)$. Treatment starter: Day $35(\mathrm{n}=5)$ except glucose and glucagon $(\mathrm{n}=$ $4)$; 56 and $84(\mathrm{n}=5)$, and $\mathrm{d} 112(\mathrm{n}=3)$.

${ }^{2}$ Calves were weaned on d 49 and prior to d 35, no starter was offered to calves. Day 35 is preweaning, thus samples were taken when calves were consuming only milk replacer and there is no dietary treatment. Calves are listed by their postweaning dietary assignment to demonstrate no preexisting differences prior to initiation of dietary treatment and to permit comparison across all 4 sampling periods. *These portal-arterial concentration differences were not different from zero.

${ }^{3}$ Probability of a greater $F$ statistic; not significant (NS) at $P>0.10$.

in blood flow to gut tissues that is disproportionate to the BW that stabilizes postweaning, perhaps because of rapid growth and development of the rumen and other splanchnic tissues. Huntington et al. (1990) summarized portal blood flow data corrected for BW that was obtained from several different sources, methods, and species. The average mature bovine portal blood flow measured using PAH dilution was $2.6 \mathrm{~L} / \mathrm{h}$ per $\mathrm{kg}$. Values reported in this study for d 112 , when converted and averaged between CON and TRT calves, were 5.1 $\mathrm{L} / \mathrm{h}$ per $\mathrm{kg}$, nearly twice that reported by Huntington et al. (1990). When the previously reported adult portal flow rate was converted from $\mathrm{BW}$ to metabolic $\mathrm{BW}$, the average flow was $11.1 \mathrm{~L} / \mathrm{h}$ per $\mathrm{kg}^{0.75}$, and the value for the current study was $15.5 \mathrm{~L} / \mathrm{h}$ per kg. ${ }^{0.75}$. Thus, whether corrected for BW or metabolic BW, the measured portal flow was still greater in this study than in other reports from adults.

The bovine portal flow rates determined by PAH and presented by Huntington et al. (1990) were measured in much larger cattle; the smallest weight reported was at $211 \mathrm{~kg}$, but the largest BW measured in the current 
Table 6. Net portal-drained visceral flux of metabolites in preweaning and postweaning dairy calves receiving calf starter with lasalocid (treatment) or without lasalocid (control) ${ }^{1}$

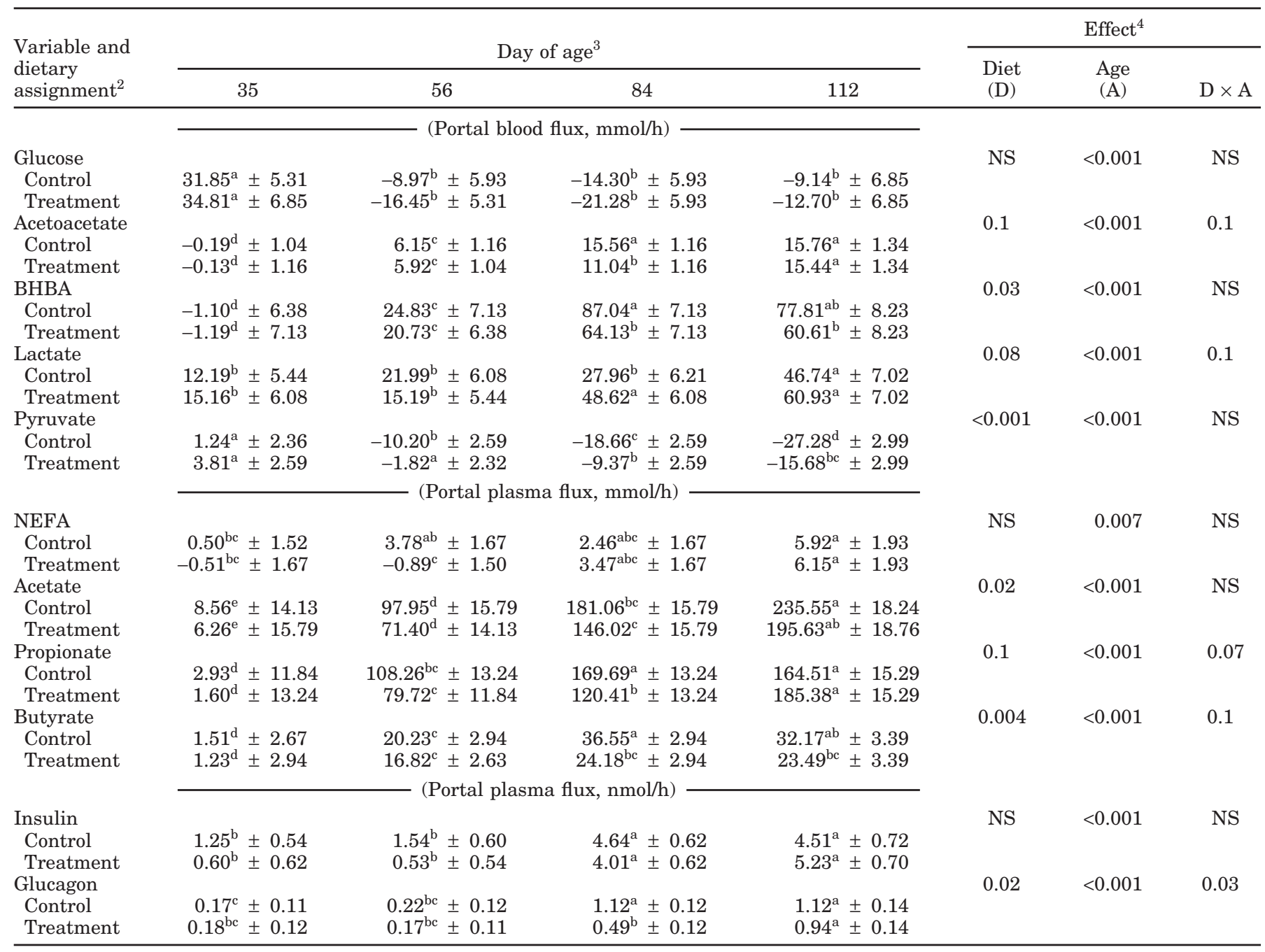

${ }^{\mathrm{a}-\mathrm{e}}$ Means within a row and between dietary treatments not sharing like superscripts are different $(P<0.05)$.

${ }^{1} \mathrm{~A}$ positive net flux indicates a net release or production of a metabolite and a negative net flux indicates net uptake or utilization of a metabolite.

${ }^{2}$ Control starter: d $35(\mathrm{n}=5)$, d 56 and $84(\mathrm{n}=4)$, and d $112(\mathrm{n}=3)$. Treatment starter: $d 35$ and $84(\mathrm{n}=4)$ except period 1 glucose $(\mathrm{n}=$ $3)$, d $56(\mathrm{n}=5)$, and d $112(\mathrm{n}=3)$.

${ }^{3}$ Calves were weaned on d 49, and prior to d 35, no starter was offered to calves. Day 35 is preweaning; thus, samples were taken when calves were consuming only milk replacer, and there was no dietary treatment. Calves are listed by their postweaning dietary assignment to demonstrate no preexisting differences prior to initiation of the dietary treatment and to permit comparison across all 4 sampling periods.

${ }^{4}$ Probability of a greater $F$ statistic; not significant (NS) at $P>0.10$.

study was during d 112 (wk 16) at $81 \mathrm{~kg}$. This observed difference in reported portal flow rates is probably an effect of calves in the current study undergoing the aforementioned rapid foregut development and growth and the consequential increase in supporting blood flow disproportionate to the rate of whole body growth. Eventually, as growth progresses, flow rates will likely adjust relative to a $\mathrm{BW}$ or metabolic $\mathrm{BW}$ basis as muscle growth catches up with the rapid increase in splanchnic tissue growth. Additionally, the DMI per kilogram of
BW is higher in young, growing animals and could also explain the higher portal blood flow rates observed when based on BW.

Ionophore supplementation in the current study did not influence blood flow rates. When high-concentrate diets supplemented with monensin were fed to Holstein steers, no effects on portal blood flow were reported (Harmon and Avery, 1987). In research using beef heifers fed high-concentrate diets supplemented with monensin, Harmon et al. (1988) did report a tendency for 
increased portal flow with ionophore supplementation. In addition, a significant decrease in portal blood flow was reported when the monensin supplement was removed from a diet of chopped alfalfa hay fed to beef steers (Harmon et al., 1988). The absence of an ionophore-related effect on blood flow was not surprising; however, little data is available for comparison that relates to calves at the developmental stage used in the present experiment and on the effects of ionophore supplementation on portal blood flow rates.

\section{Arterial Concentrations}

In agreement with Klotz and Heitmann (2006), glucose concentrations reached a nadir that coincided with weaning. Concentrations of NEFA were significantly reduced following weaning and were similar to concentrations reported for adult cattle and sheep (Bergman, 1971). Acetate, propionate, and butyrate all increased substantially postweaning and were lower in TRT than in CON calves after $d$ 35. The patterns of increasing VFA concentrations in this experiment were similar to those found by Klotz and Heitmann (2006) and Quigley et al. (1991b), but the concentrations were substantially greater. The concentrations of ketones were also greater than those previously reported by Klotz and Heitmann (2006). The decreased time between sample collections and analyses in this experiment may have reduced the potential for spontaneous decarboxylation of ACAC to acetone. The BHBA concentrations of individual calves measured in this experiment exceeded 2.0 $\mathrm{mmol} / \mathrm{L}$ on several occasions. In one individual, concentrations exceeded $3.0 \mathrm{mmol} / \mathrm{L}$, although no adverse symptoms were observed. This was of interest, because these blood concentrations exceeded the published limits for peripheral tissue utilization of ketones in mature sheep (Leng, 1965; Bergman, 1971) and the levels at which an adult typically exhibits clinical symptoms of ketosis (Bergman, 1984). However, these calves did not demonstrate the concomitant hypoglycemia observed in adults with hyperketonemia, which may be why no ketotic symptoms were observed.

\section{Portal Flux of Glucose and Glucose Precursors}

Fundamental to successful weaning is the ability of the calf to balance a decline in PDV release of glucose with a corresponding increase in hepatic release of glucose and a shift toward increased peripheral oxidation of acetate, ketones, and long-chain fatty acids. The net glucose flux shifted from a net portal release of glucose at d 35 to no significant net uptake or release of glucose during $\mathrm{d} 56,84$, and 112 . This is indicative of development of the foregut and a change in nutrient supply, because absorption of glucose from the mature foregut fermenting a fibrous diet is negligible (Bergman et al., 1970; Reynolds, 1995), and the PDV will actually have a net utilization of glucose.

Prior to weaning, lactate is the primary glucose precursor used by the preruminant liver, which has a better ability to convert lactate to glucose than does the adult liver (Donkin and Armentano, 1995). The preweaning portal release of glucose was 32 and $35 \mathrm{mmol} /$ $\mathrm{h}$ for CON and TRT calves, respectively. An additional maximum of 6 to $7.6 \mathrm{mmol} / \mathrm{h}$ of glucose could be derived from the lactate PDV release if all lactate were extracted by the liver and converted to glucose. A total of 38 to $43 \mathrm{mmol} / \mathrm{h}$ of glucose could be derived from exogenous and endogenous sources; however, this could be an underestimate, because contributions by glycerol and AA were not measured.

On $d$ 56, the PDV releases of propionate and lactate could have resulted in a maximum synthesis of 40 to $54 \mathrm{mmol} / \mathrm{h}$ and 8 to $11 \mathrm{mmol} / \mathrm{h}$ of glucose, respectively, for a total of 47 (TRT) to $65 \mathrm{mmol} / \mathrm{h}(\mathrm{CON})$. This increased at d 84 to a maximum of 85 (TRT) to $99 \mathrm{mmol} /$ $\mathrm{h}(\mathrm{CON})$ of glucose from propionate and lactate, and further increased on d 112 to a maximum of 105 (TRT) to $123 \mathrm{mmol} / \mathrm{h}(\mathrm{CON})$. The combined PDV releases of propionate and lactate could satisfactorily account for all the glucose required. Thus, if $50 \%$ of hepatic glucose production can be derived from propionate (Brockman, 1993 ) and 15 to $20 \%$ from lactate (Van der Walt et al., 1983), the ratio of gluconeogenesis from propionate to lactate would be 2.5 to $3.3: 1$. This study demonstrated similar ratios of propionate-to-lactate release postweaning. The increased PDV release of propionate and the shift in potential glucose production from lactate to propionate may explain the maintenance of euglycemia in the postweaning calf. In addition, the glucagon PDV release increased on d 84 and 112, which would support increased hepatic gluconeogenesis and further demonstrate the shift toward adult metabolism.

\section{Postweaning Alimentary Ketogenesis}

Large and rapid increases in periweaning ketone concentrations and production have previously been demonstrated in vivo and in vitro (Quigley et al., 1991a, 1992; Baldwin and Jesse, 1992). In the current experiment, large and rapid increases in ketone concentrations were observed in all veins and arteries sampled, and to the knowledge of the authors, this is the first attempt to measure net ketone fluxes periweaning. Portal fluxes of ACAC and BHBA for fed, nonpregnant, nonlactating sheep averaged 2.94 and $11.5 \mathrm{mmol} / \mathrm{h}$, respectively (Heitmann et al., 1987), which were substantially lower than the net portal appearances of ACAC 
and BHBA in 84-d-old calves reported in the current experiment $(\mathrm{CON}=15.6$ and $87.0 \mathrm{mmol} / \mathrm{h}$; $\mathrm{TRT}=11.0$ and $64.1 \mathrm{mmol} / \mathrm{h}$, respectively). However, for growing beef steers, the net portal release of BHBA was 55 $\mathrm{mmol} / \mathrm{h}$ (Huntington and Eisemann, 1988). Net portal releases of ACAC, BHBA, and butyrate on d 84 were significantly greater in CON than in TRT calves (Table 6 ). This supports previous work in which similar reductions in the PDV release of BHBA in lasalocid-supplemented wethers was reported (Housewright et al., 1994) and suggests that substrates being absorbed from the lumen of the rumen are modified, metabolized, or both by the epithelium prior to release into portal circulation.

As much as $90 \%$ of the butyrate absorbed by the rumen epithelium is metabolized to ketones (Bergman, 1990) and is an effect of butyryl-coenzyme A (CoA) synthetase (EC 6.2.1.2) having the highest activity of the activating enzymes for VFA in the rumen epithelium (Ash and Baird, 1973). The activity of the hepatic isozyme of butyryl-CoA synthetase is substantial, and the remaining butyrate that escapes metabolism by the rumen epithelium enters via the portal blood and is normally extracted by the liver. This study demonstrated that the maximal net portal release of butyrate had occurred by d 84 in both TRT and CON calves. It was also during this period that the net PDV release of propionate was greater in CON than in TRT calves. This was unexpected, because lasalocid was supplemented with the intention of reducing ketogenic and increasing glucogenic VFA. A possible explanation for this could be that the net PDV release of butyrate was also maximal.

In the presence of butyrate, large reductions in rumen epithelial propionyl-CoA synthetase (EC 6.2.1.17) activity have been observed in vitro because of the inhibitory effect of butyrate on the activating enzyme (Ash and Baird, 1973; Harmon et al., 1991). The significantly greater net portal appearance of butyrate in $\mathrm{CON}$ calves may partially explain some of the other differences seen during this sampling period (d 84). The greater net PDV release of butyrate implies that more butyrate was absorbed and thus available for ketogenesis, and would explain the significantly greater PDV releases of $\mathrm{ACAC}$ and BHBA in CON calves during this period. If the ionophore was affecting the net nutrient release into the portal vein, decreases in ruminal butyrate concentrations and absorption could result in a reduced level of inhibition of rumen epithelial propionyl-CoA synthase in the rumen epithelium. Thus, a more active propionyl-CoA synthetase would allow more absorbed propionate to be activated with a CoA moiety. The increased abundance of propionyl-CoA would result in increased metabolism of propionate to lactate by the rumen epithelium and may explain why calves receiving the ionophore had a higher net portal release of lactate but a lower net portal release of propionate at d 84 compared with CON calves.

The portal recovery of intraruminally infused propionate has been reported at 62 and $85 \%$ (Kristensen et al., 2000a,b) in sheep and at $87 \%$ in steers (Kristensen and Harmon, 2004). Thus, without ruminal VFA measurements, detection of increased PDV release of propionate is not guaranteed unless the increase in ruminal production was substantial. However, the absence of an increased PDV release of propionate with ionophore supplementation is further supported by in vivo flux data evaluating increasing butyrate concentrations on splanchnic metabolism. In both steers (Krehbiel et al., 1992) and sheep (Kristensen et al., 2000a), an increasing ruminal infusion of butyrate resulted in increasing arterial concentrations of propionate. In the current study, the greater d-84 portal flux of butyrate in CON than in TRT calves coincided with a greater arterial concentration of propionate. In addition, Kristensen and Harmon (2004) demonstrated a decreasing net portal flux of lactate with increasing ruminal absorption of butyrate. This is in agreement with both the hypothesis that increasing butyrate absorption results in a decrease in the rumen epithelial metabolism of propionate to lactate and the observations in the current study in which calves receiving ionophore had reduced PDV releases of butyrate and propionate but a concomitant increase in lactate when compared with $\mathrm{CON}$ calves.

\section{CONCLUSIONS}

The net portal appearance of ketones and VFA increased quickly with respect to dietary changes associated with weaning. The maximal net portal release of ketones was observed in 84-d-old calves, but the release of VFA continued to increase to $112 \mathrm{~d}$ of age. A significant effect of lasalocid was observed on the net portal release of nutrients in growing calves, with reductions in the release of VFA, ACAC, and BHBA in supplemented calves. Our hypothesis was that any reduction in alimentary ketogenesis and circulating ketones below the levels of maximal utilization by peripheral tissues would improve their growth and feed efficiency. However, those effects were not observed in this experiment. Calves receiving an ionophore supplement at levels typically used to treat coccidiosis may have had altered proportions of nutrients appearing in the portal blood. The lack of a response in growth or feed efficiency related to the reduction of circulating ketones may have been due to the developing calves having a greater peripheral capacity to metabolize ketones than the rates 
reported for adults, a result that warrants further investigation.

\section{ACKNOWLEDGMENTS}

All feeds used in this experiment were provided through a grant in kind from Land O'Lakes, and the authors recognize M. Fowler for his assistance in this endeavor. The authors would also like to gratefully acknowledge the dedicated support of L. Miller, N. Rohrbach, and T. T. Sun for their technical assistance; A. Reed for statistical consulting; and the research staff at Knoxville and Dairy Experiment Stations.

\section{REFERENCES}

Ankom Technology. 2003a. Method for determining acid detergent fiber. Ankom Technology Corp., Macedon, NY.

Ankom Technology. 2003b. Method for determining neutral detergent fiber. Ankom Technology Corp., Macedon, NY.

AOAC. 1999. Official Methods of Analysis. 15th ed. AOAC, Arlington, VA.

Ash, R., and G. D. Baird. 1973. Activation of volatile fatty acids in bovine liver and rumen epithelium. Biochem. J. 136:311-319.

Baldwin, R. L., VI, and B. W. Jesse. 1992. Developmental changes in glucose and butyrate metabolism by isolated sheep ruminal cells. J. Nutr. 122:1149-1153.

Baldwin, R. L., VI, and K. R. McLeod. 2000. Effects of diet forageto-concentrate ratio and metabolizable energy intake on isolated rumen epithelial cell substrate metabolism in vitro. J. Anim. Sci. 78:771-783.

Benson, J. A., C. K. Reynolds, P. C. Aikman, B. Lupoli, and D. E. Beever. 2002. Effects of abomasal vegetable oil infusion on splanchnic nutrient metabolism in lactating dairy cows. J. Dairy Sci. 85:1804-1814.

Bergman, E. N. 1984. Disorders of carbohydrate and fat metabolism. Page 412-419 in Dukes' Physiology of Domestic Animals, 10th ed. M. J. Swenson, ed. Cornell Univ. Press, Ithaca, NY.

Bergman, E. N. 1990. Energy contributions of volatile fatty acids from the gastrointestinal tract in various species. Physiol. Rev. 70:567-590.

Bergman, E. N. 1971. Hyperketonemia-ketogenesis and ketone body metabolism. J. Dairy Sci. 54:936-948.

Bergman, E. N., M. L. Katz, and C. F. Kaufman. 1970. Quantitative aspects of hepatic and portal glucose metabolism in sheep. Am. J. Physiol. 219:785-793.

Brockman, R. P. 1993. Glucose and short-chain fatty acid metabolism. Pages 249-265 in Quantitative Aspects of Ruminant Digestion and Metabolism. J. M. Forbes and J. France, ed. CAB Intl., Wallingford, UK.

Carr, S. B., and D. R. Jacobson. 1968. Method for measurement of gastrointestinal absorption in normal animals, combining portalcarotid differences and telemetered portal flow by Doppler shift. J. Dairy Sci. 51:721-729.

Donkin, S. S., and L. E. Armentano. 1995. Insulin and glucagon regulation of gluconeogenesis in preruminating and ruminating bovine. J. Anim. Sci. 73:546-551.

Durand, D., D. Bauchart, J. Lefaivre, and J. P. Donnat. 1988. Method for continuous measurement of blood metabolite hepatic balance in conscious preruminant calves. J. Dairy Sci. 71:1632-1637.

Giesecke, D., U. Beck, S. Wiesmayr, and M. Stangassinger. 1979. The effect of rumen epithelial development on metabolic activities and ketogenesis by the tissue in vitro. Comp. Biochem. Physiol. 62B:459-463.

Harmon, D. L., and T. B. Avery. 1987. Effects of dietary monensin and sodium propionate on net nutrient flux in steers fed a high concentrate diet. J. Anim. Sci. 65:1610-1616.
Harmon, D. L., T. B. Avery, G. B. Huntington, and P. J. Reynolds. 1988. Influence of ionophore addition to roughage and high-concentrate diets on portal blood flow and net nutrient flux in cattle. Can. J. Anim. Sci. 68:419-429.

Harmon, D. L., K. L. Gross, C. R. Krehbiel, K. K. Kreikemeier, C. A. Armedariz, M. L. Bauer, and R. A. Britton. 1991. Influence of dietary forage and energy intake on metabolism and acyl-CoA synthetase activity in bovine ruminal epithelial tissue. J. Anim. Sci. 69:4117-4127.

Heitmann, R. N. 1989. The use of chronic indwelling multiple catheters to study inter-organ metabolism. Dist. Feed Res. Counc. Proc. 44:5-13.

Heitmann, R. N., D. J. Dawes, and S. C. Sensenig. 1987. Hepatic ketogenesis and peripheral ketone body utilization in the ruminant. J. Nutr. 117:1174-1180.

Heitmann, R. N., and J. M. Fernandez. 1986. Auto-regulation of alimentary and hepatic ketogenesis in sheep. J. Dairy Sci. 69:1270-1281.

Housewright, B. C., R. N. Heitmann, J. C. Waller, L. N. Lembo, J. L. Campbell, and J. D. Quigley. 1994. Alterations of energy metabolite fluxes in sheep fed a concentrate based diet with or without supplemental ionophore. J. Anim. Sci. 77(Suppl. 1):191. (Abstr.)

Huntington, G. B., and J. H. Eisemann. 1988. Regulation of nutrient supply by gut and liver tissues. J. Anim. Sci. 66(Suppl. 3):35-48.

Huntington, G. B., J. H. Eisemann, and J. M. Whitt. 1990. Portal blood flow in beef steers: Comparison of techniques and relation to hepatic blood flow, cardiac output and oxygen uptake. J. Anim. Sci. 68:1666-1673.

Katz, M. L., and E. N. Bergman. 1969. A method for simultaneous cannulation of the major splanchnic blood vessels of sheep. Am. J. Vet. Res. 30:655-661.

Kaufman, C. F., and E. N. Bergman. 1971. Renal glucose, free fatty acid, and ketone metabolism in the unanesthetized sheep. Am. J. Physiol. 221:967-972.

Klotz, J. L., and R. N. Heitmann. 2006. Effects of weaning and ionophore supplementation on selected blood metabolites and growth in dairy calves. J. Dairy Sci. 89:3587-3598.

Krehbiel, C. R., D. L. Harmon, and J. E. Schnieder. 1992. Effects of increasing ruminal butyrate on portal and hepatic nutrient flux in steers. J. Anim. Sci. 70:904-914.

Kristensen, N. B., and D. L. Harmon. 2004. Effects of increasing ruminal butyrate absorption on splanchnic metabolism of volatile fatty acids absorbed from the washed reticulorumen of steers. J. Anim. Sci. 82:3549-3559.

Kristensen, N. B., S. G. Pierzynowski, and A. Danfaer. 2000a. Net portal appearance of volatile fatty acids in sheep intraruminally infused with mixtures of acetate, propionate, isobutyrate, butyrate, and valerate. J. Anim. Sci. 78:1372-1379.

Kristensen, N. B., S. G. Pierzynowski, and A. Danfaer. 2000b. Portaldrained visceral metabolism of 3-hydroxybutyrate in sheep. J. Anim. Sci. 78:2223-2228.

Lane, M. A., R. L. Baldwin, VI, and B. W. Jesse. 2002. Developmental changes in ketogenic enzyme gene expression during sheep rumen development. J. Anim. Sci. 80:1538-1544.

Lane, M. A., R. L. Baldwin, VI, and B. W. Jesse. 2000. Sheep rumen metabolic developments in response to age and dietary treatments. J. Anim. Sci. 78:1990-1996.

Leng, R. A. 1965. Ketone body metabolism in normal and underfed pregnant sheep and in pregnancy toxaemia. Res. Vet. Sci. 6:433-441.

Mellanby, J., and D. H. Williamson. 1974. Acetoacetate. Pages 1840 1843 in Methods of Enzymatic Analysis. 2nd ed. Vol. 4. H. U. Bergmeyer, ed. Verloh und Chemie, Berlin, Germany.

Nagaraja, T. G., M. B. Taylor, D. L. Harmon, and J. E. Boyer. 1987. In vitro lactic acid inhibition and alterations in volatile fatty acid production by antimicrobial feed additives. J. Anim. Sci. 65:1064.

Ortigues, I., C. Martin, D. Durand, and M. Vermorel. 1995. Circadian changes in energy expenditure in the preruminant calf: Whole animal and tissue level. J. Anim. Sci. 73:552-564. 
Quigley, J. D., III, S. I. Boehms, T. M. Steen, and R. N. Heitmann. 1992. Effects of lasalocid on selected ruminal and blood metabolites in young calves. J. Dairy Sci. 75:2235-2241.

Quigley, J. D., III, L. A. Caldwell, G. D. Sinks, and R. N. Heitmann. 1991a. Changes in blood glucose, nonesterified fatty acids, and ketones in response to weaning and feed intake in young calves. J. Dairy Sci. 74:250-257.

Quigley, J. D., III, Z. P. Smith, and R. N. Heitmann. 1991b. Changes in plasma volatile fatty acids in response to weaning and feed intake in young calves. J. Dairy Sci. 74:258-263.

Reynolds, C. K. 1995. Quantitative aspects of liver metabolism in ruminants. Pages 351-371 in Ruminant Physiology: Digestion, Metabolism, Growth and Reproduction: Proc. 8th Intl. Symp. Ruminant Physiol. W. von Engelhardt, S. Leonhard-Marek, G. Breves, and D. Giesecke, ed. Ferdinand Enke Verlag, Stuttgart, Germany.
Reynolds, P. J., G. B. Huntington, and C. K. Reynolds. 1986. Determination of volatile fatty acids, lactate, and $\beta$-hydroxybutyrate in blood by ion exchange cleanup and gas chromatography. J. Anim. Sci. 63(Suppl. 1):424. (Abstr.)

Van der Walt, J. G., G. D. Baird, and E. N. Bergman. 1983. Tissue glucose and lactate metabolism and interconversions in pregnant and lactating sheep. Br. J. Nutr. 50:267-280.

Williamson, D. H., and J. Mellanby. 1974. D-3-Hydroxybutyrate. Pages 1836-1839 in Methods of Enzymatic Analysis. 2nd ed. Vol. 4. H. U. Bergmeyer, ed. Verloh und Chemie, Berlin, Germany.

Zanzalari, K. P., R. N. Heitmann, J. B. McLaren, and H. A. Fribourg. 1989. Effects of endophyte-infected fescue and cimetidine on respiration rates, rectal temperatures, and hepatic mixed function oxidase activity as measured by hepatic antipyrine metabolism in sheep. J. Anim. Sci. 67:3370-3378. 